\title{
DISCOVERING MAGIC OF MOBILE TECHNOLOGY IN BUSINESS: STRATEGIC MARKETING PERSPECTIVE
}

Elvira Bolat, PhD, Bournemouth University, United Kingdom, ebolat@bournemouth.ac.uk

\begin{abstract}
Mobile technology penetrated all aspects of social and business existence. Studies around mobile technology mostly address the use and adoption process of mobile marketing or mobile commerce from a consumer perspective rather than from a business perspective. Another concern of majority of studies on the use of mobile technology is a focus on technical nature of mobile devices despite the fact that true magic of technology resides in its mobilisation and usage - the deployment of mobile technology. This paper aims to conceptually define and map mobile technology capabilities. Grounded theory approach was applied to collect and analyze in-depth interviews with 28 small and medium-sized enterprises from the UK, which deploy mobile technology for operational and strategic purposes. Results illustrate that mobile technology capabilities represent a set of five substantive capabilities, 1) leveraging mobile technology resources; (2) transforming capability; (3) learning capability; (4) solving problems capability; and (5) leading capability, - a set of five practices which can be employed to orchestrate successfully mobile technology resources. Through transformation of existing processes and mobile technology resources, mobile technology capabilities not only contribute to operational efficiency and effectiveness but drive strategic change within business by enabling vigilant market learning and adaptive market experimentation.
\end{abstract}

Keywords: Mobile technology; Capability approach; Resource-based view; Grounded theory; technology capability 


\section{INTRODUCTION}

Mobile technology penetrated all the aspects of social and business existence, wherein location and time independence of mobile technology extends technical and user benefits offered by fixed network and stationary IT. Existing studies (Quigley and Burke 2013; Heilig and Vob 2015) have found that mobile technology provides a quick response to market needs. Nevertheless, studies around mobile technology deployment and adoption (Donelly 2009; Sanakulov and Karjaluoto 2015) mostly address the deployment and adoption process from a consumer perspective. Studies from a business perspective focus primarily on (1) employee mobility (Lee et al. 2007; Derks et al. 2015) and (2) supply chain management (Eng 2006). Moreover majority of studies on the use of mobile technology focus on technical nature of mobile devices despite the fact that true magic of mobile technology resides in its mobilisation and usage - the deployment of mobile technology (Tarasewich et al. 2002). This paper aims to conceptually define and map mobile technology capabilities by exploring how the UK SMEs (small and medium-sized enterprises), which deliver marketing, advertising, digital architecture and digital design services, deploy mobile technology for operational and strategic purposes. A capability approach, wherein capabilities represent certain practices that are embedded within firms' routines and managerial decision-making processes (Day 1994; Winter 2003), assist in interpreting and conceptualizing empirical results. This paper treats mobile technology as a distinct category of technologies because application of mobile technology provides distinctive and unique experiences compared to business opportunities given by use of stationary and fixed network IT (Jisun and Tugrul 2010; Heilig and Vob 2015). Therefore, new concepts need to be developed for firms to make strategic choices regarding operating in a new 'mobile' environment.

\section{THEORETICAL UNDERPINNINGS}

A capability approach has become a serious and critical academic issue based on understanding a number of complex processes behind the convergence and interaction of organisational resources, skills, competences and information which lead to sustainability of a company's competitive position. According to Resource-based View (RBV) organisations are discerned as having bundles of distinctive assets, competences and capabilities that enhance positions within the competitive arena as well as help to identify sources that might assist in the acquisition and generation of new assets and capabilities (Day 1994; Wernerfelt 1984). Assets represent the tangible aspects of a company's resources, such as technologies and buildings, whereas capabilities are the invisible "glue that brings assets together and enables them to be deployed advantageously" (Day 1994, p. 38). A capability approach contemplates the strategic position of a firm, in order to manage and adapt the operational context by taking into account the company's strengths and weaknesses. Capabilities represent certain practices that are embedded within organizational routines and managerial decision-making processes (Day 1994). Dynamic capabilities research, a new paradigm that intends to reconsider organisations' strategic priorities, argues that capabilities are not static but dynamic and transformable in nature, which enables for flexible operational transformation and adaptation of firms by possessing core competencies that differentiate them from their competitors (Teece et al. 1997). Winter (2003) distinguishes between substantive and dynamic capabilities, the difference being that substantive capabilities aim at efficiency in operations and reside in daily routines and decision-making (ordinary capabilities in Winter's (2003) words), whereas dynamic capabilities are responsible for 
renewing substantive capabilities which in unexpected events or scenarios are hidden in routines or become obsolete (Zahra et al. 2006).

Aim of this study lies in conceptually defining and mapping mobile technology-specific capabilities. The introduction section has already stressed that ubiquitous technology extends the technical functionality of fixed network and stationary IT and provides further benefits to users. Existing literature has come up with a concept called 'IT capability' (Bharadwaj 2000; Sambamurthy et al. 2003). RBV represents the theoretical underpinning of a conceptualisation of IT capabilities in a substantial number of scholarly works (Ross et al. 1997; Zhang and Tansuhaj 2007), with some key contributors in this research field being Bharadwaj and Sambamurthy. According to Tarafdar and Gordon (2005, p. 2) "IT capability describes different aspects of an organisation's base of IT resources.” Nevertheless, this broad perspective is not the only view on IT capabilities. In fact, two distinct approaches have been identified within existing research to define and conceptualise IT capabilities. The majority of information research scholars (Sambamurthy et al. 2003; Bendoly et al. 2012; Ong and Chen 2013) define IT capabilities as the composition of IT systems consisting of tangible and intangible assets and competences which can be analysed on three interdependent levels: the resource level (IT infrastructure), the organising level (IT personnel, governance and co-ordination mechanisms) and the enterprise level. Enterprise-level analysis, undertaken by Huang et al. (2009), demonstrates the value perspective on IT capabilities with a strategic orientation of the organisation and leadership being responsible for utilising IT infrastructure and other related resources such as skills, knowledge and competences. As a result, the technical aspect of any particular IT-class is not of any interest for strategic decision-making - the key focus lies in the strategic mindset of the organisation in pursuing innovation and aiming at deploying the technology to benefit the firm and its clients.

Conversely, the second group of information research scholars (Wade and Hulland 2004; Chen et al. 2015) defines IT capabilities as "a firm's ability to mobilise and deploy IT resources effectively to perform” (Wang et al. 2012, p. 329). Hence, IT capabilities represent certain organisational practices or activities, such as strategic IT planning, information system development, leveraging and using an information system and lastly managing an IT function and its assets. Wang et al. (2012) particularly emphasise that IT capability is a firm's commitment and responsibility towards combining IT resources uniquely. This uniqueness then results in the creation of rare, firm-specific resources. Despite the fact that Zhang and Tansuhaj (2007) operationalize IT capability as a bundle of resources, it is acknowledged that IT resources are assets that firms invest in externally or internally (Ross et al. 1997) while IT capabilities are system-based in nature. This means that in addition to resources there has to be such elements as routines and managerial practices that enable firms to deploy IT advantageously. Studies on IT capabilities underline that apart from being an operational tool for automating information exchange and efficiency in communication, IT capabilities and resources are significant on a strategic level.

This paper treats mobile technology as a distinct category of technologies because application of mobile technology provides distinctive and unique experiences compared to business opportunities given by use of stationary and fixed network IT (Jisun and Tugrul 2010; Heilig and Vob 2015). Therefore, new concepts, including the concept of mobile technology capabilities, need to be defined for firms to make strategic choices regarding operating in a new 'mobile' environment. 


\section{RESEARCH METHOD}

To address research purpose grounded theory approach (Glaser and Strauss 1967; Corbin and Strauss 1990) was applied to collect and analyze in-depth interviews with business practitioners from the UK SMEs. Data includes semi-structured in-depth interviews with key decision-makers (business professionals, responsible for technology integration and deployment) in 28 SMEs, which deliver marketing, advertising, digital architecture and digital design services. These SMEs use mobile technology for operational daily activities, such as communication and data exchange, but also use mobile technology to deliver and/or develop a service/content. Most interviewees own and manage their businesses. However, few are responsible for particular area, devoted to understanding technological advancements: a creative director in one of the SMEs, an account manager, two new media / digital directors, and five strategic directors. To maintain ethical principles of confidentiality and anonymity of results each interviewee is labelled using [I] and adding order number. So interviewee 1 is labelled as I1. Each interview lasted from forty minutes to one and a half hour. In order to define the mobile technology capabilities concept, the author adopted and modified questions used in Dutta et al.'s (2003) paper, which studies pricing process as a capability. Open-ended interviews primarily covered aspects related to strategic business directions and mobile technology deployment within both operational daily routines and on the more strategic level of engagement (see Figure 1).

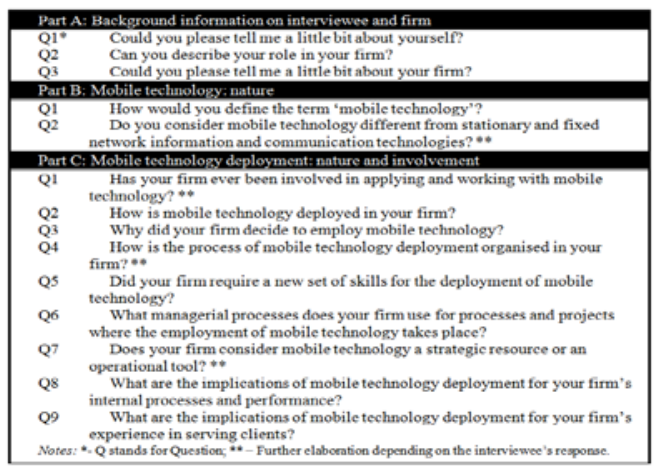

Figure 1. Interview Scenario

Employing grounded theory procedures simultaneous data collection and analysis maintains constant comparison approach that builds a rigorous theoretical conceptualisation of categories and concepts. Analysis is based on three-stage coding process as shown in Table 1.

\begin{tabular}{|c|c|c|}
\hline Coding & \multicolumn{2}{|c|}{ Overview with illustration (where applicable) } \\
\hline $\begin{array}{l}\text { 1. Open } \\
\text { Coding }\end{array}$ & $\begin{array}{l}\text { Identification of codes - detailed analysis of } \\
\text { words, sentences, or paragraphs which } \\
\text { describe the process of mobile technology } \\
\text { deployment, see the image to the right (1). } \\
\text { Coding was recorded via NVivo 10. Units of } \\
\text { information were examined for similarities } \\
\text { and differences between the interviewees' } \\
\text { claims. Where strong similarities between } \\
\text { individual concepts were found these }\end{array}$ & 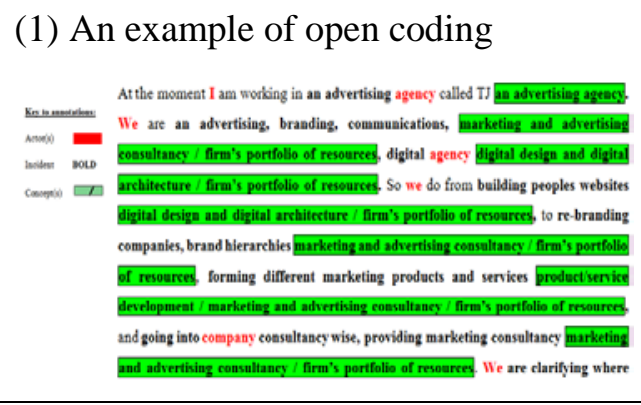 \\
\hline
\end{tabular}




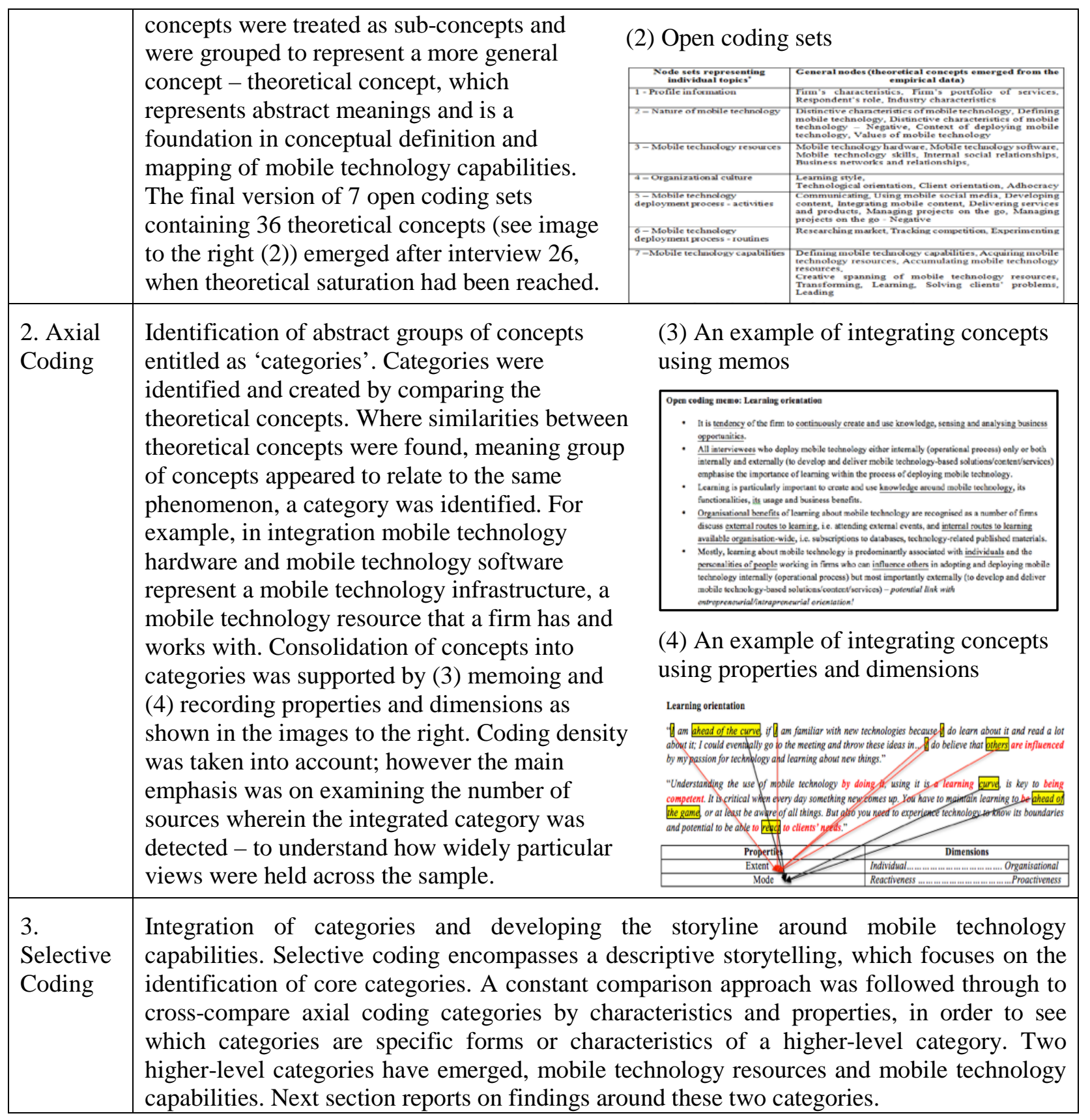

Table 1. Detailed overview and illustration of the data analysis process

\section{FINDINGS AND DISCUSSION}

\section{Mobile Technology Resources}

Twenty-eight interviewees responded positively to the extensive use of mobile technology in their business by prioritising the role of mobile technology resources in driving new ways of exploiting it accordingly. Mobile technology resources constitute a complex interactive system of tangible (physical) and intangible (organisational culture and human capital) resources. Physical resources in the form of mobile technology hardware and software establish a firm's mobile 
technology infrastructure and represent the only tangible type of asset associated with mobile technology deployment. Creative service practitioners claim that in order to deploy mobile technology infrastructure successfully, there is a need to establish an appropriate organisational set of behavioural norms and beliefs, to guide and facilitate the process of mobile technology deployment. This set forms part of an organisational culture. An organisational culture that facilitates use of mobile technology is a complex undertaking, as it combines the following four distinct but interrelated orientations: learning orientation, technological orientation, client orientation and adhocracy. Based on the interviewees' responses, these orientations can be practiced in isolation or in combination. Finally, two types of resources shape a firm's human capital, which is essential to mobile technology deployment. First, mobile technology skills and expertise represent an intangible knowledge base which can be used to create mobile technology infrastructure. Second, interviewees equate the value of social relationships, both within and outside the firm, to the successful acquisition and use of mobile technology infrastructure, mobile technology skills and to shaping organisational culture.

No existing research in relation to mobile technology deployment describes the composition of mobile technology resources as an interactive system of skills, relationships, mobile technology infrastructure and organisational culture. Nevertheless, applying RBV as a theoretical basis, studies on fixed network and stationary desktop IT identify similar groups of resources to form an overall bundle of IT resources (Bharadwaj 2000; Ong and Chen 2013; Wade and Hulland 2004; Wang et al. 2012), with the exception of organisational culture. Organisational culture either complements IT resources (Zhang and Tansuhaj 2007) or it is referred to by a different conceptual name.

\section{The Process of Mobile Technology Deployment in Focus}

Based on Wernerfelt (1984) and Day (1994), capabilities are routed in organisational processes, decision-making systems and managerial practices. This study follows a similar way of thinking, and as a result it identifies a set of mobile technology capabilities through a detailed understanding of mobile technology deployment process. It has been highlighted by business practitioners that mobile technology capabilities are unique in their nature and reside within organisational processes when the integration and reconfiguration of mobile technology resources take place. Therefore, to identify and map mobile technology capabilities it is critical to understand and analyse the process of mobile technology deployment. Collectively, 28 interviewees, whose firms deploy mobile technology, distinguish five types of activities that involve the mobilisation and use of mobile technology resources and, hence, exercise mobile technology capabilities. These five activities are (1) communicating internally and externally; (2) using mobile social media, something that is linked more to communication but covers purposes beyond that; (3) developing services and products; (4) delivering services and products and (5) managing projects on the move, irrespective of time and location. Communication, project management, service development and delivery are all areas that involve use of fixed network and stationary desktop IT. However all 28 interviewees claim that with the input of mobile technology resources all existing activities are transformed. Various authors (Jarvenpaa and Lang 2005; Sheng et al. 2005) identify communication and the coordination of operational processes through the automation of information sharing as key purpose of using mobile technology. Extant literature illustrates that the transformation of office-based project management to mobile project management has led to operational efficiencies through increased productivity (Sheng et al. 2005), operational flexibility (Lee et al. 2007) and effective communication with external and 
internal parties (Jarvenpaa and Lang 2005). However, Przybylski and Weinstein's (2013) recent study reveals that mobile devices cannot be used when discussing critical aspects of a business in comparison to face-to-face human interaction, where a close dyadic relationship is established. On the contrary, this study has not found that mobile technology deployment for communicating and managing relationships causes any interference. In fact, mobile technology is found to enrich communication and the associated experience by helping to simultaneously communicate information of different natures and formats (instant text, voice, video, images). Based on interviewee data, project management on the go represents a key activity in the process of mobile technology deployment. This is in line with a large number of studies (Axtell et al. 2008; Kietzmann et al. 2013), which explore the working on the go phenomenon. Mobility extends the possibilities of taking work beyond physical premises and allows employees to complete workrelated tasks and maintain communication whilst on the move (Battard and Mangematin 2013). This is found to be true for firms interviewed in this study.

\section{Defining and Mapping Mobile Technology Capabilities}

Going back to the main objective of this paper, conceptually defining and mapping mobile technology capabilities, this study finds that all 28 interviewees define mobile technology capabilities as the firm's "ability to embrace mobile technology effectively" [I10] and "creatively" [stated by all interviewees], "in order to provide clients with the best possible solutions, extend these solutions" [I10] and "organise and manage processes more effectively and efficiently” [14]. Key elements are the management of mobile technology infrastructure (tangible resources) through the combination of intangible resources such as skills, expertise and culture. According to interviewee 9, the ability to combine tangible and intangible resources as well as management practices is "specific to each firm, because it involves the firm's unique vision, the unique service it provides." Interviewee 8 adds that "mobile technology is fantastic, but only as far as we are able to manage it." In line with Jones et al.'s (2014, p. 142) claim that "resource alone is not source of value," this study illustrates that what matters is the application of resources. Capability implies the ability to combine resources and competences and then deploy them advantageously (Day 1994). Strangely, when defining mobile technology capabilities, the interviewees articulated their views in line with Day's (1994) conceptualisation. Mobile technology capabilities are a firm's unique practices used in exercising mobile technology resources to create a competitive advantage. To the best of author's knowledge, no currently published research has introduced the concept of mobile technology capabilities. Therefore, this definition is unique and the first to be presented. Moreover, conceptually close to studies around mobile technology deployment, the body of research on IT capabilities, which explores and explains the use of fixed network and stationary desktop IT, (Sambamurthy et al. 2003; Zhang and Tansuhaj 2007; Bendoly et al. 2012; Ong and Chen 2013) defines IT capabilities as the composition of those related to IT use resource categories, namely the IT technical base, IT skills and IT management. By introducing the definition of mobile technology capabilities, this study disagrees with conceptualising mobile technology capabilities as a combination of mobile technology resources only.

Figure 2 maps five mobile technology capabilities identified from analysis of relationships between mobile technology resources and a set of activities comprising the process of mobile technology deployment. This mapping is in line with RBV studies (Day 1994) and illustrates that capabilities reside within different marketing practices (activities in this study), such as service delivery, promotion or new product development. 


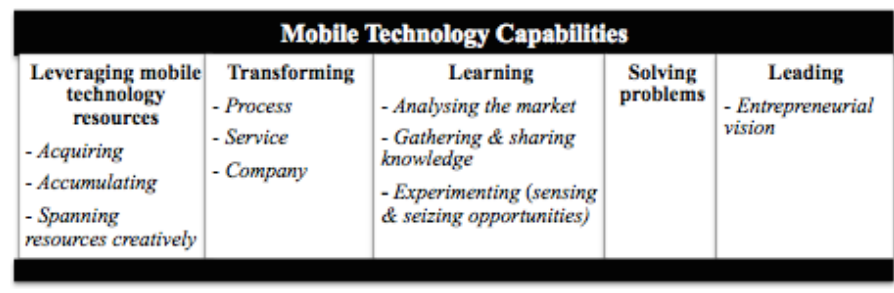

Figure 2. Mobile technology capabilities

\section{$\underline{\text { Leveraging mobile technology resources }}$}

Leveraging includes accessing mobile technology resources not only through acquisition, accumulation and outsourcing but also via the orchestration of mobile technology resources to create a unique combination of organisational resources. 28 firms have different ways of gaining access to the required mobile technology infrastructure and mobile technology skills. Some firms (I3, I2, I14, and I18) invest heavily in building their own mobile technology infrastructure and mobile technology skills: "We have changed our own software in-house within the last two years to align it with current mobile application technologies." [I3]; "We actually hired a Web developer who knows coding and mobile app design aspects” [I29].

Conversely, a number of firms (I1; I4; I7; I27) prefer to balance the risk of low returns on investment and mainly buy less pricy mobile technology infrastructure. Outsourcing is a common practice to gain access to required mobile technology infrastructure and mobile technology skills. Some interviewed firms (I6, I9, I10) outsource mobile technology infrastructure through external partnerships, since relationships are a strategically critical complementary resource to mobile technology infrastructure. These firms acquire only cost-free mobile technology software alternatives that are available externally. Some firms use outsourcing to gain access to required mobile technology skills. However, interviewee 24 stresses that the outsourcing of mobile technology skills can be "a massive risk, because we are then relying on somebody else who is not part of our team, or part of our culture." Hence, acquiring skills by employing new specialists, or alternatively accumulating mobile technology knowledge by exercising continuous learning, is less risky. Nevertheless, accumulating and acquiring mobile technology resources does not lead to the transformation of a business by introducing new revenue streams, i.e. in the form of new services. All 28 interviewees agree that creative spanning and the combination of mobile technology resources is the only way to "deliver extra value to clients" [I25] and a firm.

Leveraging mobile technology resources is a key capability and it is also found to be critical part of IT capabilities. All studies that define IT capabilities as a bundle of various IT-related resources (Bharadwaj 2000; Ong and Chen 2013) imply that IT capabilities include the ability to reconfigure and acquire IT resources. This study adds that leveraging can be done through acquisition, accumulation and outsourcing of mobile technology resources.

Transforming capability

In previous sub-section it has been highlighted that firms that use mobile technology do not really create new processes but instead transform existing activities. According to all 28 interviewees communication, project management, service delivery and development are areas that mobile technology helps to change, resulting in operational and cost efficiency, operational productivity, strategic and operational flexibility. In addition, use of mobile technology results in adaptive market experimentation via possibilities to improve service offerings through the modification of 
existing services (mobile technology as a new channel to deliver existing services) or to introduce new and radical services (mobile applications, mobile games). Adaptive market experimentation is crucial for businesses which aim to close the marketing capabilities gap by effectively engaging in just-in-time decision-making (Day 2011).

The transformation of processes through the integration of IT into operational processes is a wellknown fact (Sambamurthy et al. 2003; Zhang and Tansuhaj 2007; Bendoly et al. 2012; Ong and Chen 2013). Mobile technology, however, takes the transformation of processes, products or service portfolios and business models to a different level in comparison to fixed network and stationary IT. The difference lies in the distinctive nature of mobile technology, whereby mobility enables ubiquitous work but most importantly work on the go leading to timely and relevant decisions (Bolat 2014).

\section{Learning capability}

Learning is highlighted by all 28 firms a complex capability that firms exercise when using mobile technology. Learning incorporates the analysis of markets and industry by sharing and exchanging knowledge about mobile technology internally. This is critical to all five activities that the 28 firms perform when using mobile technology, because knowledge and its flow across individuals, teams and departments facilitate the accumulation of mobile technology resources and enable a collaborative culture. In the context of IT capabilities development Andreu and Ciborra (1996) add that learning is the only means of sensing and integrating technology into an organisation. Nevertheless, learning is not limited to knowledge accumulation and sharing but extends also to knowledge creation through experimenting, improvisation and ideation. This is particularly true when scanning, sensing and seizing opportunities, which are part of learning and the creative combination of ideas to use mobile technology. Mobile technology enables combination of vigilant market learning with adaptive market experimentation and, therefore, contributes to building a firm's innovation capability (Calantone et al. 2002; Macpherson et al. 2003)

\section{Solving problems capability}

In all 28 firms mobile technology is primarily used as a result of need to solve client or company issues. Client orientation underpins the strategic direction of all 28 firms that deploy mobile technology in order to provide bespoke solutions to clients' problems. The managing director from firm 9 comments: "We started thinking about offering location-based mobile marketing as a result of our clients coming to us and asking us to resolve a problem."

Leading capability

Creative service firms are mainly small in size, so leadership and entrepreneurial spirit have an enormous impact on business strategy and the way processes are organised (Davies and Sigthorsson 2013). In particular, the entrepreneurial vision to prioritise technology as a strategic business resource and to embrace the latest technological trends impacts on employee behaviour and the way they work. Most of business practitioners (17 out of 28 firms) interviewed in this study are passionate about mobile technology, receptive to technological tends and drive the use of mobile technology in their business: "I am somebody who is excited by technology, gadgets and communication... I am the main leader and driver. What I do creates a wake of influence. I like to go forward in business. So the whole team tries, recognises and encourages innovation." [I7]. This is in line with Feeny and Willcocks' (1998) study, which emphasises leadership and managerial competences as key to exploiting IT resources. 


\section{CONCLUSIONS AND IMPLICATIONS}

In summary, mobile technology capabilities represent a set of five subdimensions - substantive capabilities - which, through the transformation of existing processes, not only contribute to operational efficiency and effectiveness but drive strategic change within business. Winter (2003) concludes that the application and reconfiguration of resources, to solve organisational and customer problems, is a substantive capability. The advantage of this substantive capability is mainly in the way it contributes to effective and efficient operational processes within an organisation (Jones et al. 2014). Thus, it can be concluded that mobile technology capabilities with the ability to solve problems and leverage mobile technology resources are substantive in nature. Theoretically, based on the dynamic capability approach (Teece et al. 1997; Jones et al. 2014), both the transforming and the learning capabilities are dynamic in nature, because they help firms that are "confronted with changing markets or changing technologies" to "respond to a changing business environment" (Jones et al. 2014, p. 144). The nature of mobile technology capabilities, therefore, could be studied further to confirm whether it is more dynamic or ordinary in essence. This study illustrates that mobile technology capabilities aid in closing the marketing capabilities gap by enabling vigilant market learning and adaptive market experimentation. Further empirical research is required to make generalizable conclusions.

This study provides insights into experiences of mobile technology deployment from the business perspective. Managers can map their mobile technology resources and analyze current practices in deploying mobile technology resources, which will help managers to further improve their businesses.

\section{REFERENCES}

Andreu, R. and Ciborra, C. (1996). Organisational learning and core capabilities development: The role of IT. Journal of Strategic Information Systems, 5, 111-127.

Axtell, C., Hislop, D. and Whittaker, S. (2008). Mobile technologies in mobile spaces: Findings from the context of train travel. International Journal of Human-Computer Studies, 66, 902-915.

Battard, N., \& Mangematin, V. (2013). Idiosyncratic distances: Impact of mobile technology practices on role segmentation and integration. Technological Forecasting and Social Change, 80, 231-242.

Bendoly, E., Bharadwaj, A. and Bharadwaj, S. (2012). Complementary drivers of new product development performance: Cross-functional coordination, information system capability, and intelligence quality. Production and Operations Management, 21, 653-667.

Bharadwaj, A., El Sawy, O. A., Pavlou, P. A. and Venkatraman, N. (2013). Digital business strategy: Toward a next generation of insights. MIS Quarterly, 37, 471-482.

Bharadwaj, A. S. (2000). A resource-based perspective on information technology capability and firm performance: An empirical investigation. MIS Quarterly, 24, 169-196.

Bolat, E. (2014). Mobility - Unveiling the essence and value of mobility. In: European Academy of Marketing Conference 3-6 June 2014 Valencia, Spain. Valencia: European Academy of Marketing; Universitat de València, 174.

Calantone, R. J., Cavusgil, S. T. and Zhao, Y. (2002). Learning orientation, firm innovation capability, and firm performance. Industrial Marketing Management, 31, 515-524. 
Chan, F. T., \& Chong, A. Y. L. (2013). Determinants of mobile supply chain management system diffusion: a structural equation analysis of manufacturing firms. International Journal of Production Research, 51, 1196-1213.

Chen, Y., Wang, Y., Nevo, S., Benitez-Amado, J., and Kou, G. (2015). IT capabilities and product innovation performance: The roles of corporate entrepreneurship and competitive intensity. Information \& Management.

Corbin, J. \& Strauss, A. (1990). Grounded theory research: Procedures, canons, and evaluative criteria. Qualitative Sociology, 13, 3-21.

Davies, R. and Sigthorsson, G. (2013). Introducing the creative industries: From theory to practice. London; Thousand Oaks: Sage Publications.

Day, G. S. (1994). The capabilities of market-driven organisations. Journal of Marketing, 58, 37.

Day, G. S. (2011). Closing the marketing capabilities gap. Journal of Marketing, 75, 183-195.

Derks, D., Duin, D., Tims, M., \& Bakker, A. B. (2015). Smartphone use and work-home interference: The moderating role of social norms and employee work engagement. Journal of Occupational and Organizational Psychology, 88, 155-177.

Dutta, S., Zbaracki, M. J. and Bergen, M. (2003). Pricing process as a capability: a resourcebased perspective. Strategic Management Journal, 24, 615-630.

Feeny, D. F. and Willcocks, L. P. (1998). Core IS capabilities for exploiting information technology. Sloan Management Review, 39, 9-21.

Glaser, B. G. and Strauss, A. L. (1967). The discovery of grounded theory: strategies for qualitative research. New York: Aldine de Gruyter.

Hameed, K. (2003). The application of mobile computing and technology to health care services. Telematics and Informatics, 20, 99-106.

Heilig, L. and Voß, S. (2015). A Mobile Cloud Workforce Management System for SMEs. In New Horizons in Design Science: Broadening the Research Agenda (pp. 391-395). Springer International Publishing.

Huang, Y. H., Li, E. Y. and Chen, J. S. (2009). Information synergy as the catalyst between information technology capability and innovativeness: empirical evidence from the financial service sector. Information Research, 14.

Jarvenpaa, S.L. and Lang, K.R. (2005). Managing the paradoxes of mobile technology. Information systems management, 22, 7-23.

Jisun, K. and Tugrul, A. (2010). A look into the future of wireless mobile communication technologies. Journal of Technology Analysis and Strategic Management, 22, 925-943.

Jones, O., Macpherson, A. and Jayawarna, D. (2014). Resourcing the start-up business: Creating dynamic entrepreneurial learning capabilities. Oxon: Routledge.

Kietzmann, J., Plangger, K., Eaton, B., Heilgenberg, K., Pitt, L. and Berthon, P. (2013). Mobility at work: A typology of mobile communities of practice and contextual ambidexterity. The Journal of Strategic Information Systems, 22, 282-297. 
Lee, C. C., Cheng, H. K. and Cheng, H. H. (2007). An empirical study of mobile commerce in insurance industry: Task-technology fit and individual differences. Decision Support Systems, 43, 95-110.

Macpherson, A., Jones, O., Zhang, M. and Wilson, A. (2003). Re-conceptualising learning spaces: developing capabilities in a high-tech small firm. Journal of Workplace Learning, 15, 259-270.

Ong, C. S. and Chen, P. (2013). Information technology capability-enabled performance, future performance, and value. Industrial Management and Data Systems, 113, 669-682.

Przybylski, A. K. and Weinstein, N. (2013). Can you connect with me now? How the presence of mobile communication technology influences face-to-face conversation quality. Journal of Social and Personal Relationships, 30, 237-246.

Ross, J. W., Beath, C. M. and Goodhue, D. L. (1996). Develop long-term competitiveness through IT assets. Sloan Management Review, 38, 31-42.

Sanakulov, N. and Karjaluoto, H. (2015). Consumer adoption of mobile technologies: a literature review. International Journal of Mobile Communications, 13, 244-275.

Sambamurthy, V., Bharadwaj, A. and Grover, V. (2003). Shaping agility through digital options: Reconceptualising the role of information technology in contemporary firms. MIS Quarterly, 27, 237-263.

Sheng, H., Nah, F. F., and Siau, K. (2005). Strategic implications of mobile technology: A case study using Value-Focused Thinking. Strategic information systems, 14, 269-290.

Tarafdar, M. and Gordon, S. R. (2005). How information technology capabilities influence organisational innovation: exploratory findings from two case studies. Paper presented at the ECIS, Regensburg, Germany, May 26-28.

Tarasewich, P., Nickerson, R. C., \& Warkentin, M. (2002). Issues in mobile e-commerce. Communications of the Association for Information Systems, 8, 41-64.

Teece, D. J., Pisano, G. and Shuen, A. (1997). Dynamic capabilities and strategic management. Strategic Management Journal, 18, 509-533.

Wade, M. and Hulland, J. (2004). Review: the resource-based view and information systems research: review, extension, and suggestions for future research. MIS Quarterly, 28, 107-142.

Wang, N., Liang, H., Zhong, W., Xue, Y. and Xiao, J. (2012). Resource structuring or capability building? An empirical study of the business value of information technology. Journal of Management Information Systems, 29, 325-367.

Wernerfelt, B. (1984). A resource-based view of the firm. Strategic Management Journal, 5, 171180.

Winter, S. G. (2003). Understanding dynamic capabilities. Strategic Management Journal, 24, 991-995.

Zahra, S. A., Sapienza, H. and Davidsson, P. (2006). Entrepreneurship and dynamic capabilities: A review, model and research agenda. Journal of Management Studies, 43, 917-955.

Zhang, M. and Tansuhaj, P. (2007). Organisational culture, information technology capability, and performance: The case of born global firms. The Multinational Business Review, 15, 43-77. 